\title{
Röntgen rays not present in sunlight
}

\section{Carey Lea}

To cite this article: M. Carey Lea (1896) Röntgen rays not present in sunlight, Philosophical Magazine Series 5, 41:253, 528-530, DOI: 10.1080/14786449608620883

To link to this article: http://dx.doi.org/10.1080/14786449608620883

曲 Published online: 08 May 2009.

Submit your article to this journal

Џll Article views: 2

Q View related articles $₫$ 
way. Other experiments follow, in which the lead was maintained at $200^{\circ}$, and at various lower temperatures down to that of the laboratory. The following are the results:-

\begin{tabular}{|c|c|c|c|c|c|c|}
\hline \multicolumn{5}{|c|}{ Diffusivity of gold in fluid lead at $550^{\circ}$} & \multicolumn{2}{|r|}{$\begin{array}{r}k . \\
3 \cdot 19\end{array}$} \\
\hline & , & solid & , & 251 & & 0.03 \\
\hline , & $"$ & ", & ", & 200 & $\ldots$ & 0.007 \\
\hline$"$ & : & $"$ & $"$ & 16 & & 0.004 \\
\hline$"$ & ", & " & " & & & 0.000 \\
\hline
\end{tabular}

The experiments at the ordinary temperature are still in progress, but there is evidence that slow diffusion of gold in lead occurs at the ordinary temperature. The author points out that if clean surfaces of lead and gold are held together in vacuo at a temperature of only $40^{\circ}$ for four days, they will unite firmly, and can only be separated by the application of a load equal to onethird of the breaking strain of lead itself.

The author thinks it will be considered remarkable that gold placed at the bottom of a cylinder of lead, 70 millims. long (which is to all appearance solid), will have diffused to the top in notable quantities at the end of three days. He points out that at $100^{\circ}$ the diffusivity of gold in solid lead can readily be measured, though its diffusivity is only $1 / 100,000$ of that in fluid lead at a temperature of $500^{\circ}$. He also states that experiments which are still in progress show that the diffusivity of solid gold in solid silver, or copper, at $800^{\circ}$ is of the same order as that of gold in solid lead at $100^{\circ}$.

He concludes by warmly thanking Mr. A. Stansfield, B.Sc., who assisted him in all but the earlier portion of the work, and by expressing the hope that the experiments described in the paper will show that the diffusion can readily be measured in solid metals, and that they will carry one step further the work of Graham.-Proceedings of the Royal Society, February 20, 1896, being an abstract of the Bakerian Lecture.

RÖNTGEN RAYS NOT PRESENT IN SUNLIGHT. BY M. GAREY LEA.

If Prof. Röntgen's views as to the nature of the $x$-rays are correct, it would seem that they ought to be found amongst the many forms of radiant energy received from the sun, and various observers have thought that they so found them. Some experiments, the most important of which will be here briefly stated, do not seem to support this opinion.

1. A very sensitive dry plate (S. 27) was placed between the leaves of a book so that 100 leaves and the red paper cover should be between the sensitive film and the sunlight. The book was then packed in a box-frame to exclude all light from the sides. A large and thick lead star was then fastened on the outside of the book and the arrangement was exposed to exceptionally bright sunshine from 11 A.M. to sunset, March 7. The plate when put 
into a developing-bath behaved as if unexposed. A prolonged development did not bring out a trace of an image of the lead star.

It will be remembered that Prof. Röntgon found that the $x$-rays penetrated easily through a book of 1000 printed pages. Indeed 6. Moreau has recently stated that in his hands the $x$-rays had penetrated through "several metres" of cardboard". So that the above experiment seems to be very significant.

2. A piece of sheet aluminium 1.2 millim. thick was aceurately fitted into a frame. A very sensitive plate was placed behind it and a lead star in front. With three hours' exposure not a trace of an image could be obtained. This experiment was varied by substituting thin aluminium-foil for the plate, also by using bromide-paper as the sensitive surface. No images in any case were obtained.

3. The suu's rays or some portion of its radiation passes readily through wood if the latter is not too thick. Thus, through a piece of white pine $\frac{3}{16}$ of an inch thick, images that could readily be developed were obtained by three minutes' exposure to afternoon sunlight. With half an hour's exposure the inages were brilliant.

A panel about 12 inches square was removed from an inside shutter and replaced with a piece of white pine $\frac{1}{4}$ inch thick. When the room was thoroughly darkened, reddish light could be seen to pass through the board. So that wood of this thickness is plainly trauslucent to the sight.

The sun's ligbt may be examined for $x$-rays also by fluorescence.

4. The panel just described was replaced by one of stout bookboard. With the sun shining on this book-board directly and not through glass, paper marked with a saturated solution of barium platinocyanide exbibited no indications of fluorescence when placed behind the board.

5. Three thicknesses of Bristol-board were pasted together, a circle was cut out, to one side of which barium platinocyanide was applied. The circle was then placed in a pasteboard tube (an arrangement, I believe, proposed by Prof. Magie). When the sun was looked at through this tube the barium salt exhibited fluorescence. But the interposition between the card and the sun of very thin aluminium-foil sufficed to cut off the fluorescence.

These concurrent results seem to indicate the absence of $x$-rays from sunlight.

Charles Henry* quotes an opinion of H. Poincaré that all bodies whose phosphorescence is sufficiently intense emit in addition to luminous rays the $x$-rays of Röntgen, whatever may be the cause of their fluorescence. Henry quotes confirmatory experiments of his own made with zinc sulphide.

It seemed worth while to ascertain if this principle is of general application. A dilute solution of uranin was exposed to sunlight,

* C. R. exxii. p. 238: quoted Chem. News, Feb. 21, 1896, p. 85 (No. 1891).

$+C . R$. cxxii. p. 312; Chem. News, Feb. 28, 1896, p. 98.

Phil. Mag. S. 5. Vol. 41. No. 253. June 1896. 20 
using a large surface of solution so as to get the best effect. A short distance over the surface was placed a sensitive film protectod by aluminium-foil $\frac{1}{10}$ of a millimetre in thickness and with a lead star interposed. Two hours' exposure gave no result. The experiment was repeated with acid solution of quinine, with which five hours' exposure gave no result.

I have also examined the Welsbach light for $x$-rays. This light is usually burned under a chimney which increases the brightness but interposas glass between the source of light and the sensitive film. Even without a chimney the light is bright. The experiment was therefore made both ways. No $x$-rays could be detected. Nothing capable of passing through aluminium-foil $\frac{1}{10}$ of a millimetre in thickness by five hours' exposure to the uncovered flame. - American Journal of Soience, May 1896.

\section{ON A NEW AREOMETER. BY L.-N. VANDEVYVER.}

The instrument is of glass, and consists of a cylinder divided in two parts by a horizontal watertight diaphragu $\mathrm{C}$. The part $B$ forms a small reservoir, closed at $D$ by a ground stopper. To the cylinder is attached a stem carrying a scale which may be graduated in different ways. We shall assume that this scale is graduated for liquids heavier than water, with densities between 1.00 (water) and $1 \cdot 6$, for instance.

The liquid whose specific gravity is to be determined serves as ballast.

Suppose it desired to verify the initial point of the graduation. For this purpose the instrument is inverted, and the part $B$ is filled with distilled water at a temperature $t$; the stopper is inserted without allowing air to enter; the apparatus can then be held upright without any fear of the stopper falling out; it is wiped and placed in a cylinder containing distilled water at the same temperature $t$. The point to which it sinks should correspond to the point 1.00 of graduation on the stem.

The same process is repeated for the liquid whose density is to be determined, care being taken to clean the apparatus each time it is used; distilled water being always used for the immersion. The liquid introduced into $\mathrm{B}$ being denser than water the total weight of the apparatus is greater, and it sinks to a greater depth, giving a now level which represents

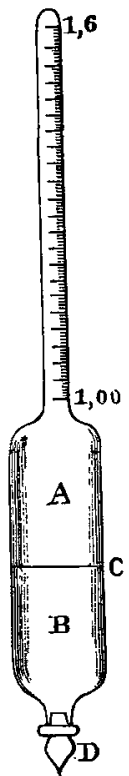
the density.

By taking for extreme limits of the scale densities which are sufficiently near together, the densimeter may be made very sensitive. 